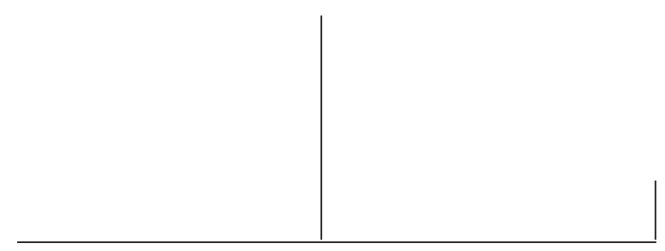

Rev. Latinoam. Psicopat. Fund., IV, 4, 81-91

\title{
A esfinge em questão
}

\author{
Eliane Robert Moraes
}

Em diversas definições, monstros e mulheres aparecem como seres incompletos e imperfeitos, cujas anatomias revelariam uma realização inacabada da natureza. A partir dessa hipótese, este texto analisa a Esfinge que figura no mito de Édipo para interrogar as razões da supremacia do herói sobre o monstro. Tal supremacia supõe uma idealização do homem que, abstrata e universal, é desmentida por cada ser na sua existência concreta e singular.

Palavras-chave: Monstro, mulher, Esfinge, Édipo, Hegel

* Trabalho apresentado no V Congresso Brasileiro de Psicopatologia Fundamental, setembro de 2000, em Campinas, SP, na Mesa-redonda: "A medicina e as formas corporais do sofrimento". 


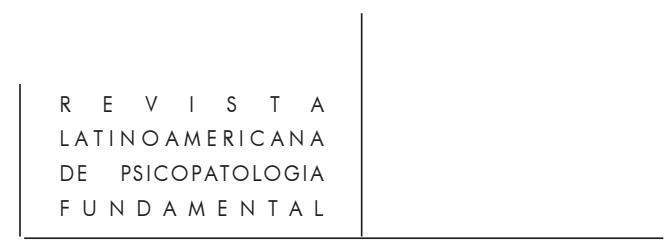

... d'une façon ou de l'autre, à une époque ou à l'autre, l'espèce humaine ne peut pas rester froide devant ses monstres.

Georges Bataille, "Les écarts de la nature"

Nos tratados ocidentais de teratologia, antigos ou modernos, os mutilados e deformados figuram quase sempre como um capítulo obrigatório. Entre os monstros biológicos incluem-se, com freqüência, os anões, os corcundas, os cegos, os aleijados e outros portadores de defeitos físicos; entre os seres imaginários destaca-se igualmente uma série de criaturas às quais faltam um ou mais órgãos. Tudo se passa como se houvesse uma continuidade entre as formas monstruosas e as imperfeições anatômicas, de modo que as deformidades do corpo humano parecem estar na origem da própria idéia de monstro.

Entre as diversas definições de monstro, uma das mais freqüentes consiste em considerá-los seres inacabados ou, como prefere Kappler, “... seres a quem falta algo de essencial”. Essa concepção já se faz presente em várias fontes da antiguidade, como Plínio ou Aristóteles. Lucrécio, por exemplo, ao descrever o começo do mundo em De natura rerum, define tais criaturas unicamente por meio de caracteres negativos:

Numerosos também foram os monstros que a terra nessa época esforçouse por criar e que nasciam com aspecto e membros estranhos - tal como o andrógino, intermediário entre dois sexos, que não é um nem outro e não pertence a nenhum -, seres privados de pés ou desprovidos de mãos, ou ainda mudos e sem boca, ou que ocorria serem cegos e sem olhar, ou cujos membros cativos permaneciam inteiramente grudados ao corpo e nada podiam fazer, nem se mover, nem evitar o perigo, nem prover às suas necessidades. ${ }^{1}$

Nessa definição, o monstro aparece como um homem que, vivendo nos primórdios da constituição do mundo, ainda não se completou: ele é privado ou desprovido de alguma capacidade ou órgão que se torna indispensável na própria qualificação do humano. Inacabadas, as espécies descritas em De natura rerum remetem a uma perturbação no curso da geração do homem, a um acidente natural, ou a "um desvio da natureza", para adiantarmos o termo com que 


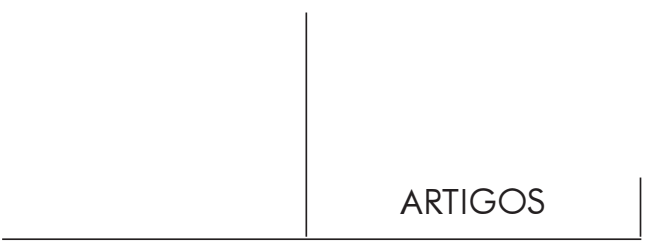

Georges Bataille define tais criaturas. Não deixa de ser expressivo que essa concepção continue sendo operante em distintas condições históricas: em que pese o grande intervalo entre épocas, certas definições de seres monstruosos que figuram nos tratados do século XVI guardam bastante proximidade com a de Lucrécio. ${ }^{2}$

O mais conhecido desses tratados talvez seja Des monstres et prodiges, escrito em 1573 por Ambroise Paré, que realiza uma das primeiras compilações ocidentais visando a sistematizar o conhecimento sobre tais criaturas. O ponto de partida de Paré, explicitado no primeiro prefácio à obra, reside na idéia de monstro como "coisas que aparecem contra o curso da Natureza". Talvez por julgar excessivamente genérica sua definição inicial, no segundo prefácio, datado de 1579 , o autor a substitui por "coisas que aparecem além do curso da natureza", estabelecendo ainda uma tênue distinção - que sugere igualmente uma aproximação - entre monstros, prodígios e mutilados.

Ainda assim, na escala estabelecida por Paré (1971: 3), as fronteiras que separam os três tipos de criaturas permanecem um tanto turvas: os prodígios são "coisas totalmente contrárias à natureza" e os mutilados

... são cegos, zarolhos, corcundas, coxos ou os que têm seis dedos na mão ou nos pés, ou menos de cinco, ou juntas unidas, ou braços muito curtos, ou o nariz muito encravado como têm os golfinhos, ou os lábios grossos e invertidos, ou fechamento da parte genital das meninas por causa do hímen, ou carnes suplementares, ou que sejam hermafroditas, ou que tenham manchas, ou verrugas, ou lúpias, ou outra coisa contra a Natureza.

Além disso, nos três exemplos das coisas que aparecem além do curso da natureza - ou seja, já na segunda definição de monstro -, o autor evoca "uma criança que nasce com um só braço, outra que tem duas cabeças, e outros membros, além do ordinário". Portanto, a indeterminação entre o que é contra, totalmente contrário ou além da natureza parece fazer com que os prodígios e os mutilados retornem aos domínios do monstruoso, reiterando a concepção inicial. ${ }^{3}$

Sabe-se que De monstres et prodiges fazia parte de um compêndio intitulado De la génération de l'homme. A obra foi dedicada ao Duque de Uzès, cujo interesse pelos "problemas da geração" parece ter precipitado o volume suplementar que, na dedicatória, Paré apresenta simplesmente como "coletânea de diversos monstros, tanto dos que são produzidos nos corpos de homens e mulheres, quanto outros animais

2. Vale lembrar que a obra de Lucrécio, e particularmente De natura rerum, começa a tornar-se conhecida em alguns países da Europa a partir do século XVI, conforme afirma Sergio Bertelli em Rebeldes, libertinos y ortodoxos en el barroco, p. 86.

3. Vale lembrar ainda que à substituição do prefácio não parece ter correspondido qualquer modificação no texto, conforme observou Jean Céard, nas notas a Des monstres et prodiges, p. 151 , nota 7 . 


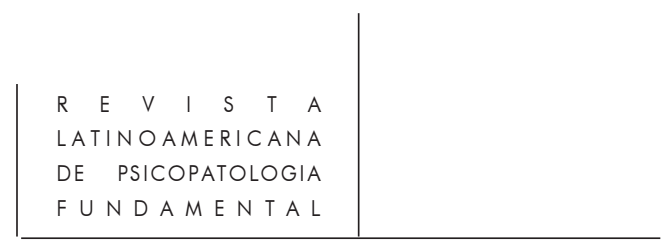

terrestres, marítimos e aéreos" (Ibid.: XI). Assim sendo, a própria concepção do livro associa a geração dos monstros à dos seres humanos. Interessa, aqui, notar a reiteração de um motivo que, de Lucrécio a Paré, das fontes mais antigas às mais modernas, talvez possa ser sintetizado numa breve fórmula: o monstro descende do homem.

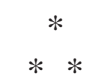

O primeiro capítulo de De monstres et prodiges é inteiramente dedicado ao exame das causas dos monstros. Paré é sucinto:

As causas dos monstros são várias. A primeira é a glória de Deus. A segunda, sua ira. A terceira, a demasiada quantidade de semente. A quarta, sua quantidade demasiado pequena. A quinta, a imaginação. A sexta, a estreiteza ou pequenez da matriz. A sétima, o assentar-se inconveniente da mãe que, em estando prenhe, permanece sentada durante longo tempo com as coxas cruzadas ou apertadas contra o ventre. A oitava, por queda ou golpe dado contra o ventre da mãe que está prenhe. A nona, por enfermidades hereditárias ou acidentais. A décima, por podridão ou corrompimento da semente. A décima primeira, por mistura ou cruzamento de sementes. A décima segunda, por artifício das más disposições da parteira. A décima terceira, pelos demônios ou diabos. (Ibid.: 4)

A classificação de Paré, de grande riqueza tanto do ponto de vista histórico quanto literário, ${ }^{4}$ parece centrar-se sobretudo nas causas humanas da geração de monstros, embora o faça emoldurando-as estrategicamente entre Deus, que encabeça a lista, e os demônios, que a fecham. Ora, grande parte das razões enumeradas referese especificamente à geração do próprio homem que, por algum acidente incapacidade da parteira, posições inconvenientes durante a gravidez, quedas, golpes ou enfermidades -, não teria completado seu curso de forma satisfatória.

Segundo Jean Céard, a noção de monstro proposta em De monstres et prodiges circunscreve-se exclusivamente ao uso do homem, sendo, portanto, esboçada "à medida de sua inteligência". Ciente dos limites da "frágil razão humana", em sintonia com o pensamento de sua época, Paré não teria qualquer ambição de propor uma explicação totalizante. Isso porque, mesmo excetuando-se as razões divinas ou

4. Inscrita na história, essa justaposição de condições, a princípio incompatíveis, revela aquela disposição de pensamento típica do século XVI que aliava a necessidade de compreender o mundo com os medos mais irracionais, colocando lado a lado as ordenações limitadas e racionais e as enumerações angustiantes de múltiplas possibilidades. Do ponto de vista literário - e com os desdobramentos filosóficos que toda boa literatura engendra - basta nos lembrarmos da conhecida "enciclopédia chinesa", citada por Jorge Luís Borges, que remete o leitor aos limites epistemológicos de seu próprio pensamento. 


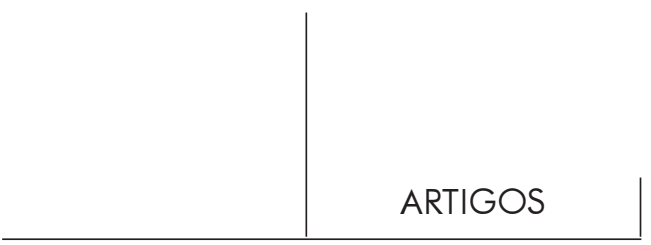

diabólicas que determinam tais criaturas, haveria na ordem natural uma série de operações cujos mecanismos escapariam à compreensão do homem: “... esse domínio do oculto, segundo o termo empregado correntemente no século XVI, representa o lugar onde a natureza, no segredo de sua atividade, ocupa-se em produzir efeitos ininteligíveis ao homem, efeitos que Paré nomeia precisamente como monstruosos".

Inacessíveis à compreensão humana, esses mecanismos secretos da natureza visariam, em última instância, a manutenção da harmonia universal. Na base de tal concepção reside a idéia de que o universo é um "grande Todo", para empregarmos a expressão de Paré, que se organiza através de uma trama perfeita de relações e correspondências: assim como "o mundo celeste reflete o mundo dos homens, as ordens inferiores existem como reflexo das ordens superiores". Nesse jogo de equilíbrios e contrastes, as formas monstruosas seriam o reflexo invertido do corpo humano que, segundo Paré, representa a "mais perfeita obra de Deus, contendo em si a harmonia absoluta das coisas contrárias".

Mas a natureza, observa ainda o autor de De monstres et prodiges, "tende sempre àquilo que é o mais perfeito, e não ao contrário, tornar imperfeito o que é perfeito". É por essa razão que por vezes assiste-se ao caso paradoxal de "certas mulheres que degeneram em homens", no qual o efeito monstruoso é produzido com o objetivo de atingir a perfeição das formas: “... como não encontramos jamais uma história verdadeira de algum homem que tenha se tornado mulher, é porque a Natureza não tende jamais a engendrar fêmea, mas sempre um macho, como o mais perfeito", reitera o autor. (Céard, 1971: XXXIII, XLI, XXXIX)

A tópica nos remete novamente às relações entre os monstros e a mutilação dos corpos. Paré conhecia a tese aristotélica de que a mulher é um homem mutilado, como comprovam suas citações do livro sobre a Geração dos animais. Considerando a supremacia do sêmen masculino na geração, Aristóteles concebe a forma ideal como reprodução idêntica de seu protótipo: quanto maior a distância do modelo original, maior será a imperfeição. O primeiro grau dessa diferença - que nos monstros chegaria ao estágio máximo - seria dado na formação de um indivíduo feminino em vez do masculino. A anatomia da mulher revelaria, assim, uma realização inacabada da natureza e, embora necessária, imperfeita.

Ora, tanto na hipótese genética de Aristóteles como na de Paré, a mulher contém em si o mesmo princípio de incompletude que caracteriza os monstros. Entre a anatomia feminina e as formas monstruosas haveria tão-somente uma diferença de grau, não de essência: a produção de uma fêmea seria, desse modo, o primeiro passo - ou o primeiro desvio da natureza - no caminho da formação de criaturas imperfeitas. Seguindo essa hipótese, não seria equivocado formular uma segunda suposição: o monstro descende da mulher.

$$
\text { * * }
$$




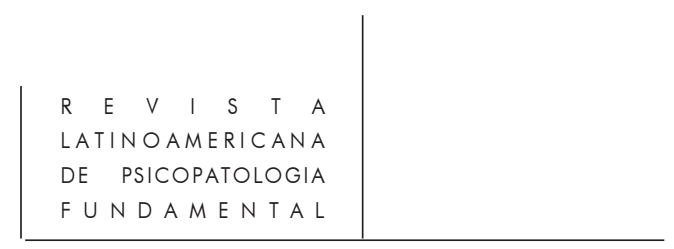

Monstro feminino por excelência, a esfinge que figura no mito de Édipo pode ser interrogada a partir dessas considerações sobre as criaturas teratológicas. Por tratar-se de um monstro fundante da nossa cultura, não deixa de ser digno de nota o fato de que, nas diversas interpretações do mito, ela é freqüentemente eclipsada pelo herói que a derrota.

Segundo a interpretação clássica de Hegel (1944: 163), no pensamento ocidental Édipo representa a metáfora do homem que toma consciência de si, realizando os desígnios da célebre inscrição grega, "conhece-te a ti mesmo". Ao responder à interrogação enigmática da esfinge, lançando-a ao abismo, o herói vence a opacidade das formas monstruosas projetadas pelo espírito nas quais "subsiste o respeito diante da interioridade obscura e obtusa da vida animal que resiste à reflexão".

Os seres ambíguos e misteriosos da arte egípcia constituem, ainda segundo o filósofo alemão, o discurso enigmático por excelência; neles é o próprio espírito que surge como monstruoso, participando ao mesmo tempo das qualidades humanas e animais: “... tem-se a impressão de que o espírito humano deseja se livrar da força brutal e obtusa sem conseguir romper por completo os laços que o unem e reúnem àquilo que ele não é". Por isso, os monstros encontrados nos antigos símbolos egípcios "contêm implicitamente muito, explicitamente pouco": ou seja, "são trabalhos que foram realizados com o objetivo de obter conhecimentos sobre si mesmo, mas que permaneceram a meio caminho desse objetivo". (Ibid.: 72)

À medida que a esfinge faz do símbolo um enigma, ela concentra a essência mesma do simbolismo, evocando um estágio do pensamento em que as formas ambivalentes e obscuras ainda não teriam sido superadas. Se interroga o espírito é porque ela mesma, na qualidade de monstro, se constitui enquanto um enigma: inferior ao conceito, o símbolo revelaria uma ambigüidade de base, manifesta numa busca de consciência que não se completa e, dessa forma, reitera o mistério subjacente à vida animal. Nesse sentido, a esfinge representaria o oposto de Édipo: ela é hostil ao homem e à humanidade.

Ora, quando Édipo destrói a esfinge, não é apenas o monstro em si que sucumbe ao espírito humano, mas tudo aquilo que ele representa enquanto "símbolo do simbolismo", conforme precisou Hegel. Com esse ato, o herói supera o estágio simbólico para elevar-se ao plano conceitual do pensamento. Ao eliminar as formas monstruosas, inadequadas à vida humana, ele conquista "um conhecimento que só se obtém pelo espírito": a consciência de si resulta de um processo de depuração das formas que parte da negação da animalidade. Não se trata, pois, de um homem que alarga suas fronteiras compartilhando a mesma natureza dos animais, mas o contrário: Édipo funda um domínio próprio e exclusivo no qual "o espírito recebe uma existência sensível e natural que lhe é adequada". (Ibid.: 151)

Nada mais distante do Édipo que aparece na mitologia surrealista que as formulações de Hegel. Aliás, o que efetivamente resta do herói grego no imaginário surreal 


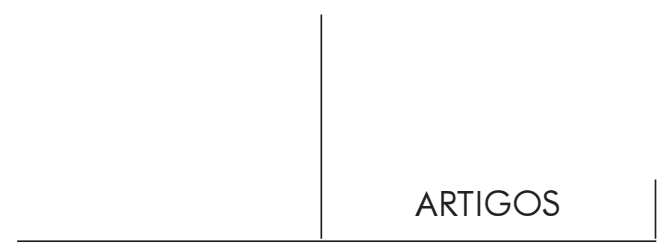

é muito pouco: embora evocado com alguma frequiência nas colagens de Max Ernst (1982: 140) e nas gravuras de Kurt Seligmann, não raro numa atitude esquiva e receosa, sua aparição é sempre eclipsada pela esfinge. Reduzido à galeria dos símbolos mais corriqueiros da modernidade - como confirma o título de uma colagem de La femme 100 têtes: "A esfinge e o pão de cada dia visitam o convento" - Édipo ocupa ali uma posição insignificante, contrariando sua ênfase no pensamento moderno.

Antes de mais nada, aos olhos dos surrealistas o vencedor da esfinge figura como o grande precursor de um despotismo masculino que tem, como corolário, o triunfo da razão e da consciência de si sobre o caos primitivo. Isso bastaria para colocá-lo às margens de uma mitologia que exalta a figura feminina como signo augural do "espírito novo".

À reabilitação da esfinge na cosmologia surreal corresponde a condenação definitiva de Édipo:

... eu sempre me admirei - diz Breton numa entrevista - com a insignificância daquela interrogação diante da qual Édipo assume grandes ares... Mas ela nos leva ao coração do mito grego, mais precisamente a uma das primeiras maquinações que tendem a persuadir o homem de que ele é o senhor da sua situação, que nada pode superar seu entendimento ou bloquear seu caminho, a envaidecê-lo, enfim, fazendo-lhe valer dos meios de elucidação dos quais dispõe, à custa de lhe ocultar o sentido de seu próprio mistério. (Ibid.: 210)

Muito mais mobilizador que o suposto enigma decifrado por Édipo, é no tríptico polinésio de Gauguin - "De onde viemos? Quem somos? Para onde vamos?" - que os surrealistas encontram as autênticas interrogações humanas: "Nessa tripla questão reside o único enigma verdadeiro diante do qual aquele colocado pela lenda na boca da esfinge torna-se uma formulação ridícula". Mais ainda: longe de pretender dar uma resposta à questão, como fez o herói grego, a regra geral do grupo sempre foi, como observou Vitrac, "recusar-se a qualquer expediente que deixe de provocar a interrogação inesgotável da esfinge e manter-se na situação de adivinhá-la".5

Manter o estado de interrogação significa manter o mistério das formas monstruosas, em consonância com a afirmação de Jarry que, em 1895, já pontificava: “... chamo monstro toda beleza de origem inesgotável” (Ibid.: 178). Nesse retorno ao símbolo revela-se o desejo de conservar intacto o caos primitivo da floresta virgem e da selva mental de onde surgem os monstros, pelo menos até que uma verdadeira solução para o enigma seja vislumbrada. E, por certo, não teria sido Édipo a formulála.

Entendem-se, portanto, as razões pelas quais o grande herói do pensamento moderno é, aqui, reduzido à bagatela de "pão de cada dia" e a simulacro de si

5. Citado por Maillard-Chary, Le bestiaire des surréalistes, p. 210 e 211. 
mesmo. Diante disso, não causa surpresa o fato de Édipo jamais aparecer em pé na iconografia surrealista, mas sempre sob uma forma amputada ou mortificada. É significativo ainda que a transmutação moderna do herói mantenha uma só característica da figura mítica original: o corpo mutilado, que o faz retornar ao primado do monstruoso.

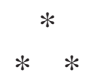

Tal associação entre Édipo e o monstro, que aproxima o herói da esfinge, não é apenas uma fabulação surrealista. Ela já se faz presente no próprio mito original, sobretudo se recordarmos que os mutilados e deformados participam das classificações das criaturas teratológicas. Vale lembrar, portanto, aquilo que se oculta na tese de Hegel: Édipo porta uma deformação de origem que, inclusive, determina seu nome, significando "pés inchados". A ela vem se acrescentar, como sabemos, uma mutilação definitiva que ocorre quando ele arranca os próprios olhos e se torna cego.

Em outras palavras: no sentido inverso à interpretação hegeliana, essa aproximação sugere que ninguém - nem mesmo o herói fundante da nossa cultura - escapa dos domínios do monstruoso. Isso nos faz retornar ao capítulo da teratologia.

Num artigo dedicado ao tema, Georges Bataille (1970: 228) parte de uma obra publicada em 1561 - as Histoires prodigieuses de Pierre Boaistuau, um contemporâneo de Paré - para dizer que

... entre as coisas que podem ser contempladas sob a concavidade dos céus, nada se vê que mais desperte o espírito humano, que mais seduza os sentidos, que mais aterrorize, que mais provoque nas criaturas admiração ou terror que os monstros, os prodígios e as abominações através dos quais as obras da natureza são vistas invertidas, mutiladas e truncadas.

O texto vem acompanhado de seis gravuras extraídas de um compêndio teratológico do século XVIII, nas quais se vêem imagens de irmãos siameses unidos pelo crânio, de uma criatura composta de dois corpos e um só rosto, ou de um anão cujas mãos e pés saem diretamente do tronco.

Bataille vale-se das teses renascentistas para propor que a teratologia humana nada mais é que um prolongamento das formas anatômicas naturais. À medida que "... a responsabilidade de tais desvios, embora sejam considerados contranatureza, é indiscutivelmente da natureza", os monstros biológicos deixam de ser uma alteridade absoluta da figura humana para evidenciarem sua inevitável ameaça interna. E é por essa razão - posto que tal "dialética das formas" se inscreve na própria natureza que, "de uma forma ou de outra, de uma época à outra, a espécie humana não consegue manter-se indiferente diante de seus monstros".

Considerado na sua particularidade, cada rosto humano seria, no limite, monstruoso: assim como o ideal de beleza "estaria à mercê de uma definição tão 


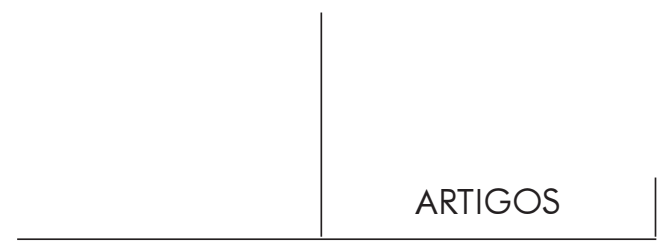

clássica como a de medida comum", continua Bataille, "os monstros estariam situados em oposição à regularidade geométrica, tal como ocorre nas formas individuais, embora de um modo irredutível" (Ibid.: 229-230). Regularidade geométrica que, sem dúvida, equivale aos ideais abstratos sem possibilidade de realização concreta na humanidade: diante de "seus monstros", a figura humana se decompõe irremediavelmente para oferecer ao homem a sua imagem informe, imperfeita e irremediavelmente monstruosa.

Ora, as considerações de Bataille sobre os "desvios da natureza" são interessantes justamente porque vêm reiterar a crítica dos surrealistas ao predomínio de Édipo em detrimento da esfinge. A diferença entre ambos, na qual Hegel supõe uma hierarquia, poderia ser indicada inicialmente nos seguintes termos: sendo homem do conceito, o domínio de Édipo é o da idéia, que opera por abstrações e compõe ideais; já a esfinge representa o simbolismo, cujo domínio é o do imaginário, mais próximo do pensar poético e artístico por operar com imagens. Cumpre lembrar também que o monstro obedece ao imperativo do detalhe, reiterando sua irredutibilidade às abstrações.

Interessa sublinhar, no pensamento de Bataille, a concepção de que o monstro - neste caso, a esfinge - é hostil à idéia de humanidade não só por representar o simbolismo, mas sobretudo por permanecer circunscrito ao campo das particularidades. O funcionamento do monstro não pode admitir abstrações pois essas atuam no sentido de apontar universalidades e estabelecer generalizações às quais ele não responde. Assim, o ideal de Édipo, que segundo Hegel diria respeito ao gênero humano, opõe-se a qualquer criatura teratológica porque esta é invariavelmente uma singularidade e jamais um ser genérico.

Cada monstro é, por definição, um degenerado. Isso significa que ele não pertence a gênero algum, só podendo ser compreendido como criatura absolutamente única. Tal é a diferença maior entre Édipo e a esfinge. Contudo, o que o monstro parece propor ao herói da mitologia grega, se nos dispusermos a escutá-lo, é que seus pés inchados e seus olhos enucleados também fazem dele uma particularidade. Em resumo: não há homem concreto que responda de forma absoluta ao ideal abstrato e genérico de "homem".

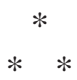

E a mulher, vale perguntar à guisa de conclusão, qual seria seu lugar nessa história? Antes de mais nada, é preciso atentar ao fato de que o monstro também nos obriga a recusar a idéia de mulher genérica. Diante das interrogações que as criaturas teratológicas nos lançam, na afirmação de sua singularidade, não seria possível postularmos um ideal universal feminino, que negaria igualmente a particularidade de cada ser. 


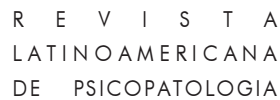

Contudo, estando mais próxima do monstro por deixar descoberta a sua incompletude, a mulher parece funcionar nesse esquema como um intermediário entre o genérico e o particular, operando as diferenças dentro do gênero humano. Desnecessário lembrar a identidade fundamental entre ela e a materialidade efetiva dos corpos, o que remete necessariamente a cada sujeito na sua existência concreta. $\mathrm{O}$ domínio feminino seria, portanto, bem mais poroso às particularidades do que o suposto domínio masculino, identificado genericamente ao "humano". E tal hipótese não deixa de supor uma série de conseqüências que nos permitem pensar a sensibilidade contemporânea.

Seguindo a trilha de Bataille, talvez seja menos importante aproximarmos o monstro da mulher do que apontar uma via feminina de demarcação das diferenças num mundo cada vez mais hostil às expressões das singularidades. É o que talvez faça mais sentido numa época em que as particularidades concretas de cada ser tendem a se dissolver rapidamente, não só nas generalizações absolutas, mas também nas identidades coletivas que postulam os direitos da "mulher", do "negro", do "gay", do "sadomasoquista", e daí por diante. Numa época, como essa em que vivemos, na qual toda afirmação do singular se vê ameaçada pela ideologia de supostas "minorias" a qual atende pelo nome de "politicamente correto". Ideologia formalista, moralista e rigorista que faz recordar, em muitos aspectos, um certo conservadorismo contra o qual ela diz se insurgir.

A aproximação entre monstros e mulheres funciona, portanto, como lembrança de que o princípio de incompletude, em vez de negar nossa humanidade é, antes, um de seus traços fundantes. Nesse sentido, a falta que identifica genericamente a mulher deve ser compreendida bem mais como um operador de diferenças do que como medida comum ao gênero. Trata-se, nesse caso, de um vazio original, princípio de toda criação, que abre espaço para a construção da singularidade, entendida sempre como irredutível ao todo.

Como figuras dessa incompletude, mulheres e monstros vêm lembrar a diferença que cada um de nós porta ao integrar o gênero humano. Vêm lembrar que somos, cada qual, um "desvio" em relação ao suposto homem genérico e universal - e que, nessa qualidade, cabe a cada um de nós a aventura sensível de uma existência. Se dermos ouvidos às interrogações colocadas pela esfinge, num mundo ainda dominado pelas respostas de Édipo, talvez seja possível redefinir a idéia de humano para então nos reencontrarmos - sendo monstros.

\section{Referências}

BAtAille, Georges. Les écarts de la nature. In Oeuvres complètes. Paris: Gallimard, 1970. t. I. Bertelli, Sergio. Rebeldes, libertinos y ortodoxos en el barroco. Trad. Marco Aurelio Galmarini. Barcelona: Península, 1984. 


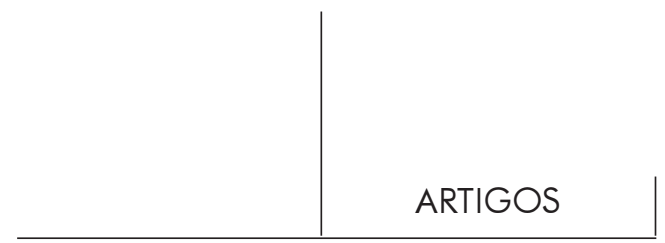

CÉARD, Jean. Introdução a Des monstres et prodiges. Genebra: Droz, 1971.

ERnst, Max. La femme 100 têtes. In Escrituras. Trad. Pere Grimferrer e Alfred Sargatal. Barcelona: Polígrafa, 1982.

Hegel, G.H.F. Esthétique. Trad. S. Jankélevich. Paris: Aubier, 1944. t. II.

KAPPler, Claude. Monstros, demônios e encantamentos no fim da Idade Média. Trad. Ivone Castilho Benedetti. São Paulo: Martins Fontes, 1994.

Maillard-Chary. Le bestiaire des surréalistes. Paris: Presses de la Sorbonne Nouvelle. PARÉ, Ambroise. Des monstres et prodiges. Genebra: Droz, 1971.

\section{Resumos}

En diversas definiciones monstruos y mujeres aparecen como seres incompletos e imperfectos, cuyas anatomías revelarían una realización inacabada de la naturaleza. Partiendo de esta hipótesis, este texto analiza la Esfinge que figura en el mito de Edipo para interrogar las razones de la supremacía del héroe sobre el monstruo. Tal supremacía supone una idealización abstracta y universal del hombre, que es desmentida por cada ser en su existencia concreta y singular.

Palabras clave: Monstruos, mujeres, Esfinge, Édipo, Hegel

Dans diverses définitions, les monstres et les femmes apparaîssent comme des êtres incomplets et imparfaits dont l'anatomie révèlerait une réalisation inachevée de la nature. A partir de cette hypothèse, ce texte analyse le Sphinx qui figure dans le mythe d'Oedipe, pour interroger les raisons de la suprématie du héros sur le monstre. Une telle suprématie suppose une idéalisation de l'homme qui, abstraite et universelle, est démentie par chaque être humain dans son existence concrète et singulière.

Mots clés: Monstres, femmes, Sphinx, Oedipe, Hegel

In various definitions, monsters and women appear as incomplete and imperfect beings whose anatomies reveal an unfinished work of nature. Based on this hypothesis, the present article analyzes the Sphinx in the Oedipus myth to inquire into the reasons for the supremacy of the hero over the monster. This supremacy supposes an abstract and universal idealization of man that is contradicted by each being in its concrete and singular existence.

Key words: Monster, woman, Sphinx, Édipo, Hegel 